\title{
Micro-epidemiology of Plasmodium falciparum malaria: Is there any difference in transmission risk between neighbouring villages? Yazoumé Yé*1, Catherine Kyobutungi ${ }^{1}$, Valérie R Louis ${ }^{2}$ and Rainer Sauerborn ${ }^{2}$
}

\author{
Address: ${ }^{1}$ African Population and Health Research Centre, PO Box 10787-00100 GPO Nairobi, Kenya and 2Department of Tropical Hygiene and \\ Public Health, University of Heidelberg, Medical School, Heidelberg, Germany \\ Email: Yazoumé Yé* - yyazoume@aphrc.org; Catherine Kyobutungi - ckyobutungi@aphrc.org; Valérie R Louis - Valerie.Louis@urz.uni- \\ heidelberg.de; Rainer Sauerborn - rainer.sauerborn@urz.uni-heidelberg.de \\ * Corresponding author
}

Published: 19 April 2007

Malaria Journal 2007, 6:46 doi:10.1 186/1475-2875-6-46

This article is available from: http://www.malariajournal.com/content/6/l/46

(C) 2007 Yé et al; licensee BioMed Central Ltd.

This is an Open Access article distributed under the terms of the Creative Commons Attribution License (http://creativecommons.org/licenses/by/2.0), which permits unrestricted use, distribution, and reproduction in any medium, provided the original work is properly cited.
Received: I December 2006

Accepted: 19 April 2007

\begin{abstract}
Background: Malaria control strategies are designed as a solution for either the whole region or the whole country and are assumed to suit every setting. There is a need to shift from this assumption because transmission may be different from one local setting to another. The aim of this study was to assess the risk of clinical malaria given the village of residence among under-five children in rural north-western Burkina Faso.
\end{abstract}

Methods: 867 children (6-59 months) were randomly selected from four sites. Interviewers visited the children weekly at home over a one-year period and tested them for fever. Children with fever were tested for malaria parasites. An episode of clinical malaria was defined as fever (axillary temperature $\geq 37.5^{\circ} \mathrm{C}$ ) + parasites density $\geq 5,000$ parasites/ $\mu$ l. Logistic regression was used to assess the risk of clinical malaria among children at a given site of residence.

Results: Children accumulated 758 person years (PYs). Overall, 597 episodes of clinical malaria were observed, giving an incidence rate of 0.79 per PY. The risk of clinical malaria varied amongst the four sites. Taking one village as reference the odds ratio for the other three sites ranged from 0.66 ; $95 \% \mathrm{Cl}: 0.44-0.98$ to $1.49 ; 95 \% \mathrm{Cl}$ : I.10-2.0I.

Conclusion: Malaria control strategies should be designed to fit the local context. The heterogeneity of transmission should be assessed at the district level to allow cost-effective resource allocation that gives priority to locations with high risk. Functional routine health information systems could provide the necessary data for context specific risk assessment.

\section{Background}

Malaria remains a public health concern worldwide and especially in sub-Saharan Africa (SSA), where it is a major killer among children under five years of age [1-4]. This is despite local, national, and international efforts to control the disease. A country or a region in the country may be classified as endemic or holo-endemic or meso-endemic depending on the transmission intensity [5]. Subsequently, control strategies are designed for the whole region or country and are assumed to suit every local setting therein. However, the transmission may be different from one local setting to another within the same region 
or geographical locality and interventions designed at the regional or national level may fail to meet needs on the ground. It may be assumed that health districts would focus resources for malaria control proportionate to risk of malaria transmission in specific localities if they were aware of which localities were more threatened than others. Knowledge of malaria risk at a local level may prove more informative for formulating control strategies by supporting resource allocation decisions at the health district level.

There is evidence that malaria transmission risk varies even on the smallest scale. Wang et al have demonstrated inter-city variation of malaria prevalence among school children [6]. In Dar es Salaam, malaria prevalence was shown to gradually increase as one moved from the city centre to the periphery. Similar findings were observed in Ouagadougou and Abidjan [6,7]. These studies were, however, cross-sectional in nature and were limited to urban areas. Some studies have shown that the transmission risk as measured by the entomological inoculation rate (EIR) may differ between neighbouring localities, but few studies have been carried out on the risk in terms of outcomes in the human host. The aim of this study was, therefore, to assess whether there were differences in the risk of clinical malaria (defined as axillary temperature $\geq$ $37.5^{\circ} \mathrm{C}$ and parasites density $\geq 5,000$ parasites/ $\mu$ l) among children under-five in one town and three villages in north-western Burkina Faso.

\section{Methods}

Study sites

The study was conducted in the town of Nouna and the villages of Cissé, Goni, and Kodougou. These four sites are part of the Nouna Demographic Surveillance System (DSS) area [8], which is located in Kossi province in the north western part of Burkina Faso [9]. Kossi province (area 5,000 sq km) is considered a holo-endemic area. The villages are about 19-44 kilometres from each other's centre.

\section{Study population}

A cohort of 867 children (Cissé: 171, Goni: 240, Kodougou: 191 and Nouna: 265) aged 6 to 59 months, participated in the study. The children were selected from each site by means of cluster sampling of households using a sampling frame generated from the DSS database. The sample size was set to detect inter-site differences in the incidence of clinical malaria of at least 10\% (if they exist), with $80 \%$ power and $95 \%$ confidence, and in anticipation of $15 \%$ loss to follow up. The Local Ethics Committee of Nouna approved the study.

\section{Clinical malaria data}

Four trained-interviewers, one based in each site, visited individual children at home every week from December 2003 to November 2004. This follow up period of 12 months covered one dry and one rainy season. At each visit, the interviewers measured the axillary temperature of the child and collected a blood sample (by finger prick) from any child with fever. In addition, they asked the mother/caretaker about the use of mosquito nets and collected data on housing conditions including the presence of animals, and potential breeding sites within a 30-metre radius of the house. This information was cross-checked by observation.

A field supervisor regularly collected the forms and blood slides from the field and transported them to the Nouna Health Research Centre laboratory. Two laboratory technicians read the blood slides stained with Giemsa to determine the parasite count. In cases of non-agreement, a biologist read the slide. This happened with only $2 \%$ of the slides. Parasite density was estimated by counting parasites in 100 fields and equating the found value to 0.25 $\mu \mathrm{l}$. The outcome of interest was clinical malaria episode, defined as axillary temperature $\geq 37.5^{\circ} \mathrm{C}$ plus a parasite density $\geq 5,000$ parasites $/ \mu \mathrm{l}$. This case definition is similar to the one used by previous studies in this region $[10,11]$.

For ethical reasons, interviewers treated every child with fever for malaria, in accordance with national treatment guidelines. When fever persisted for two days or other symptoms surfaced, they referred the child to the nearest health facility. The project covered all related costs.

\section{Data management and quality control}

Data entry clerks entered the data into a relational database developed in Microsoft Access. The data entry screen was similar to the data collection forms and included automatic consistency checks. At the field level, supervisors visited the interviewers and checked the filled forms before sending them for data entry. At the data entry level, a data entry supervisor randomly checked 5\% of data entered each day. The critical proportion of error was set to the $5 \%$ level. Data was to be re-entered completely if the proportion of found errors was above 5\%. However, this situation did not occur. Clean data were exported to STATA 8.1 for statistical analysis.

\section{Statistical modelling}

Logistic regression was used to estimate the odds ratio (OR) of clinical malaria associated with residing in one of the four sites using the Goni site (site with the most episodes of clinical malaria) as a reference. The multivariate model included a number of potential confounders and these are shown in Table 1. 
Table I: List and description of variables included in the logistic regression model

\begin{tabular}{|c|c|c|c|c|}
\hline Factors & Variable & Description & Type & Value \\
\hline Outcome & $\begin{array}{l}\text { Clinical malaria } \\
\text { episode }\end{array}$ & $\begin{array}{l}\text { Fever }+ \text { Parasites density } \geq 5000 \\
\text { parasites } / \mu \mathrm{l}\end{array}$ & Binary & $0=$ No, $I=$ Yes \\
\hline \multicolumn{5}{|c|}{ Explanatory } \\
\hline & Site & Site of residence of the child & Categorical & $\mathrm{I}=$ Nouna 2 = Cissé, $3=$ Goni (ref) $4=$ Kodougou \\
\hline \multicolumn{5}{|c|}{ Co-variables } \\
\hline & Gender & Sex of the child & Binary & $0=$ Male $($ ref $), I=$ Female \\
\hline & Age & Age group in months & Categorical & $0=<12 \mid=12-23,2=24-353=36-47,4=48+($ ref $)$ \\
\hline & Ethnicity & $\begin{array}{l}\text { Ethnic group to which the child } \\
\text { belongs }\end{array}$ & Categorical & $\begin{array}{l}1=\text { Peulh }(\text { ref), } 2=\text { Mossi, } 3=\text { Marka, } 4=\text { Bwaba, } 5=\text { Samo, } \\
6=\text { other }\end{array}$ \\
\hline & Net use & $\begin{array}{l}\text { Did the child sleep under a mosquito } \\
\text { net the since the last visit? }\end{array}$ & Binary & $0=$ No $($ ref), $I=$ Yes \\
\hline & Water point & $\begin{array}{l}\text { Presence of a well within 30-metre } \\
\text { radius of the house }\end{array}$ & Binary & $0=$ No $($ ref),$I=$ Yes \\
\hline & Farm & $\begin{array}{l}\text { Presence of a farm within } 30 \text { - metre } \\
\text { radius of the household }\end{array}$ & Binary & $0=$ No (ref), $I=$ Yes \\
\hline & $\begin{array}{l}\text { Animal } \\
\text { enclosure }\end{array}$ & $\begin{array}{l}\text { Presence of an animal enclosure } \\
\text { within 30-metre radius of the house }\end{array}$ & Binary & $0=$ No $($ ref $), I=$ Yes \\
\hline & Breeding site & $\begin{array}{l}\text { Presence of an open water body } \\
\text { within 30-metre radius of the house }\end{array}$ & Binary & $0=$ No (ref), $I=$ Yes \\
\hline & Season & $\begin{array}{l}\text { Dry season }=\text { November to May, } \\
\text { Rainy season }=\text { June to September }\end{array}$ & Binary & $0=$ Dry season I = Rainy season \\
\hline
\end{tabular}

ref $=$ reference categories

The model was built as follows:

$\log i t(\pi)=\beta_{0}+\beta_{1}$ Site_Cisse $_{i}+\beta_{2}$ Site_Nouna $_{i}+$ $\beta_{3}$ Site_Kodougou $_{i}+\beta_{4}$ Gender_Female $_{i}+\beta_{5}$ Age $_{-}<12_{i}+$ $\beta_{6}$ Age_12 $-23_{i}+\beta_{7}$ Age_24 $-35_{i}+\beta_{8}$ Age_36 $-47_{i}+$ $\beta_{9}$ Ethnic_Mossi $_{i}+\beta_{10}$ Ethnic_Marka $_{i}+\beta_{11}$ Ethnic_Bwaba $_{i}+$ $\beta_{12}$ Ethnic_Samo $_{i}+\beta_{13}$ Ethnic_other $_{i}+\beta_{14}$ Netused_Yes $_{i}+$ $\beta_{15}$ Waterpoint_Yes $_{i}+\beta_{15}$ Farm_Yes $_{i}+$ $\beta_{16}$ Animalenclosure_Yes $_{i}+\beta_{17}$ Breedingsite_Yes $_{i}+$ $\beta_{18}$ Season_Rainy $_{i}$

Where $\pi_{i}$ is the predicted probability of having clinical malaria of the $i$ th child; the odds of the same child will be $\frac{\pi_{i}}{1-\pi_{i}} . \beta_{0}$ is the intercept and $\beta_{1} \ldots \beta_{17}$ the regression coefficients of the independent variables (name following each coefficient). The odds ratio associated with a given coefficient is the exponential of the respective beta coefficient. Site_Cissé compared to Goni (reference) is the exponential of $\beta_{1}\left(\mathrm{OR}_{\text {Site_Cissé }}=\exp \left(\beta_{1}\right)\right)$.

\section{Results}

\section{Study population characteristics}

The 867 children were from 427 households and the average number of children per household was two. Kodougou had the largest mean number of children per household (2.5). Overall, females were more (52.5\%) than males but the sex distribution across the sites was not significantly different $(p$ value $=0.420)$. Similarly, the age distribution did not differ between sites ( $p$ value $=0.938$ ). Participants were almost equally distributed between the age groups except for the age group below 12 months $(9.2 \%)$ (Table 2 )

\section{Follow up status}

During the one-year observation period, 28 children left the cohort, either due to death (15) or due to migration out of the study sites (13) (Figure 1). Although fifty two home visits were planned per child, on average each child was observed for 45.6 weeks because children were not always present at each visit. As a result, the person time observed is different from the number of children. Overall, there were 758.0 observation person-years (PYs). The PYs per site were for Nouna (219.6), Kodougou (163.1) Goni (224.4), and Cissé (150.9).

\section{Clinical malaria incidence}

The total number of observed episodes of fever was 1,635, giving an incidence of 2.2 episodes per PY $(1,635$ episodes/758.0 PYs). This incidence was similar in all sites (Cissé $=2.1$, Goni $=2.3$, Kodougou $=2.2$, and Nouna $=$ 2.0). Out of the 1,635 fever episodes, 597 were confirmed as being due to clinical malaria, giving an incidence rate of 787.6 per 1,000 PYs. The highest incidence rate was observed in Goni (935.8 per 1,000 PYs), followed by Kodougou (821.6 per 1,000 PYs), Cissé (775.3 per 1,000 PYs) and Nouna (751.4 per 1,000 PYs).

\section{Site of residence as a risk factor for clinical malaria}

The results of the logistic regression (Table 3 ) showed that compared to Goni, children living in Nouna and Cissé 
Table 2: Descriptive characteristics of the study population in four sites of the Nouna DSA, Burkina Faso, from 01.12 .2003 to 30.11 .2004

\begin{tabular}{|c|c|c|c|c|c|c|}
\hline & \multirow[b]{2}{*}{ All (\%) } & \multicolumn{4}{|c|}{ Sites } & \multirow[b]{2}{*}{$*^{2}$ test } \\
\hline & & Cissé (\%) & Goni (\%) & Kodougou (\%) & Nouna (\%) & \\
\hline $\mathbf{N}$ & 867 & $|7|$ & 240 & 191 & 265 & - \\
\hline Household & 427 & 74 & 125 & 77 & $|5|$ & \\
\hline $\begin{array}{l}\text { Children/ } \\
\text { household** }\end{array}$ & 2.0 & 2.3 & 1.9 & 2.5 & 1.8 & \\
\hline Gender & & & & & & $p$ value $=0.420$ \\
\hline Female & $455(52.5)$ & $103(60.2)$ & I I 6 (48.3) & $98(5 \mid .3)$ & $138(52.1)$ & \\
\hline Male & $4 \mid 2(47.5)$ & $68(39.8)$ & $124(51.7)$ & $93(48.7)$ & $127(47.9)$ & \\
\hline Age in months & & & & & & $p$ value $=0.938$ \\
\hline$<12$ & $80(9.2)$ & 14 (8.2) & $19(7.9)$ & 15 (7.9) & $32(12.1)$ & \\
\hline $12-23$ & $200(23.1)$ & $39(22.8)$ & $57(23.8)$ & $43(22.5)$ & $61(23.0)$ & \\
\hline $24-35$ & $202(23.3)$ & $36(21.1)$ & $59(24.6)$ & $43(22.5)$ & $64(24.2)$ & \\
\hline $36-47$ & $211(24.3)$ & $40(23.4)$ & $58(24.2)$ & $50(26.2)$ & $63(23.8)$ & \\
\hline $48+$ & $174(20.1)$ & $42(24.6)$ & 47 (19.6) & $40(20.9)$ & $45(17.0)$ & \\
\hline
\end{tabular}

*Mantel-Haenszel chi-Square test for a difference across sites, **Average number of children per household

$(\mathrm{OR}=0.70 ; 95 \% \mathrm{CI}: 0.52-0.95$ and $\mathrm{OR}=0.66 ; 95 \% \mathrm{CI}$ : 0.44-0.98 respectively, had a significantly lower risk of clinical malaria, but those residing in Kodougou had significantly higher risk (OR $=1.49 ; 95 \%$ CI 1.10-2.01). Among other covariates, age, "presence of farm", "ethnicity" and "rainy season" had significant effects on the clinical malaria risk. The risk of clinical malaria decreased significantly with increasing age. The risk was 2.3 times and 1.6 times higher in children below 12 months and those between 36-47 months respectively compared to those aged $48+$ months. Children of Mossi and Samo ethnicity had a significantly lower risk of malaria infection compared to Peulh (OR $=0.56 ; 95 \% \mathrm{CI}$ : 0.37-0.85 and OR 0.51 ; 95\%CI: 0.31-0.85 respectively). Children of other ethnicities had a lower but not statistically significant risk. Farming activity within a 30 metre-radius of the house was associated with significantly higher odds of clinical malaria (OR = 1.46; 95\%CI: 1.21-1.78). Children were more likely to have clinical malaria during the rainy season compared to the dry one $(\mathrm{OR}=2.19 ; 95 \% \mathrm{CI}$ : $1.82-2.65)$.

\section{Discussion}

There were differences in the risk for clinical malaria between the four sites as shown by the number of episodes per PY and the odds of clinical malaria given the site of residence. The largest incidence rate was observed in Goni, which had about 1.2 times higher incidence than Nouna and Cissé. The odds ratio of clinical malaria for this site was also higher even though the highest odds ratio was found in Koudougou. Such differences were observable despite the relative proximity of the four sites since they are within a 19-44 kilometre radius of each other.
The lower incidence observed in Nouna and Cissé and Kodougou compared to Goni could be explained by differences in the ecological settings of these sites. Goni is located in a plain where there is seasonal rice farming which creates favourable habitats for mosquitoes. Kodougou is a village about 200 metres from a permanent river, which serves as a water source for traditional irrigation. Proximity to irrigated and flooded agriculture practices have been reported to be highly associated with malaria infection [12-14]. The semi-urban setting of Nouna could explain its comparatively lower incidence of clinical malaria. Indeed, urban settings are reported to be less prone to malaria transmission compared to rural settings [15] due to the pollution of water bodies therein. These polluted waters are unsuitable as breeding sites for the malaria vector. The findings of low incidence of clinical malaria from Cissé are surprising. Cissé is located next to a forest and is surrounded by a swamp during the rainy season. These conditions are suitable for an increased risk of malaria transmission. A possible explanation of the low observed risk could be presence of cattle, which serve as an alternative host of the malaria vector. Cattle keepers with their attendant animal enclosures within the villages are the main inhabitants of Cissé. An investigation of the feeding preference of malaria vectors is needed to determine the fraction of vectors feeding on animals.

Regarding the results from the logistic regression, the pattern observed in the crude incidence rate of clinical episodes per 1000 PYs was maintained after accounting for variables that may influence this distribution. Compared to children living in Goni, those living in Kodougou were more likely to have clinical malaria while those from Cissé and Nouna were significantly less likely to have it. Differ- 


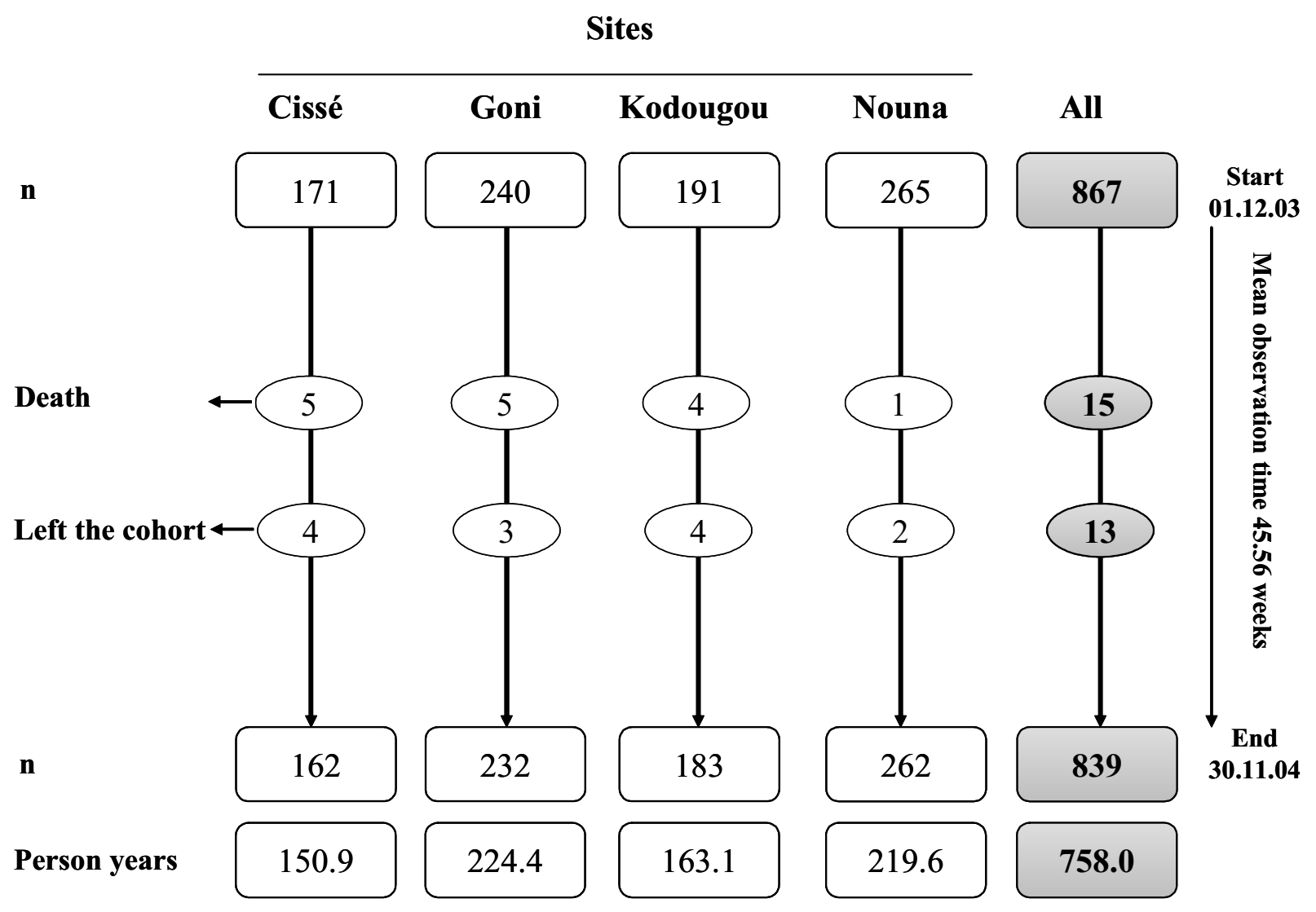

Figure I

Outcome of the follow up of study participants in four sites of the Nouna DSA, Burkina Faso, from 0I.I2.2003 to 30.II.2004.

ences in the ecological settings of the sites as discussed above could still explain these differences in risk. Other covariates showed different effects on the risk of contracting clinical malaria.

Older children were better protected than the young ones. The odds were much higher in the age group below 12 months. This was not surprising because children below 6 months have immunity acquired from the mothers, which they progressively loose, as they grow older. Reyburn et al [16] reported a high risk of severe malaria in the age group below 12 months. With increasing age, children develop partial immunity and become less susceptible, although below five years this immunity remains weak.

Studies have suggested that ethnicity has a significant effect on the clinical malaria risk. Studies in this area have shown that the Peuhl (also known as Fulani) are less sus- ceptible to malaria due to their reduced genetic susceptibility compared to other ethnicities $[17,18]$. However, our findings did not confirm this. Mossi and Samo have significantly lower risk than the Peuhl. Ethnic differences observed in previous studies may be attributable to differences in local ecological settings since people of the same ethnic group tend to aggregate in the same village. Previous studies did not assess this latter factor. Studies specifically designed to explore this association in this region may be of interest, as understanding genetic susceptibility to clinical malaria could prove useful for vaccine development.

Self-reported usage of a mosquito net was surprisingly not associated with a decrease in clinical malaria risk among children as has been extensively reported in other studies [19-24]. The question was precise enough to get the required information because interviewers asked mothers 
Table 3: Odds ratios of clinical malaria infection among children given their site of residence

\begin{tabular}{|c|c|c|c|c|c|c|}
\hline Variables & & PYs & Episodes & OR & p-value & $95 \% \mathrm{Cl}$ \\
\hline All & & 758.0 & 597 & & & \\
\hline \multicolumn{7}{|l|}{ Explanatory } \\
\hline \multirow[t]{4}{*}{ Site } & Goni & 224.4 & 210 & I & & \\
\hline & Nouna & 219.6 & 165 & $0.70 *$ & 0.023 & $0.52-0.95$ \\
\hline & Cissé & 150.9 & 117 & $0.66^{*}$ & 0.042 & $0.44-0.98$ \\
\hline & Kodougou & 163.1 & 134 & $1.49 * *$ & 0.009 & $1.10-2.01$ \\
\hline \multicolumn{7}{|l|}{ Co-variables } \\
\hline \multirow[t]{2}{*}{ Gender } & Male & 367.6 & 280 & 1 & & \\
\hline & Female & 390.4 & 317 & 1.01 & 0.889 & $0.86-1.19$ \\
\hline \multirow{5}{*}{ Age in months } & $>12$ & 14.7 & 10 & $2.28^{*}$ & 0.015 & I.18-4.42 \\
\hline & $12-23$ & 149.3 & 144 & $2.09 * * *$ & 0.000 & $1.63-2.67$ \\
\hline & $24-35$ & 168.4 & 164 & $1.98 * * *$ & 0.000 & $1.10-2.02$ \\
\hline & $36-47$ & 178.7 & 145 & $1.60 * * *$ & 0.000 & $1.25-2.04$ \\
\hline & $48+$ & 246.8 & 134 & I & & \\
\hline \multirow[t]{6}{*}{ Ethnicity } & Peulh & 151.5 & 123 & I & & \\
\hline & Mossi & 219.2 & 176 & $0.56 * *$ & 0.007 & $0.37-0.85$ \\
\hline & Marka & 247.7 & 206 & 0.81 & 0.280 & $0.55-1.19$ \\
\hline & Bwaba & 59.6 & 53 & 0.74 & 0.238 & $0.45-1.22$ \\
\hline & Samo & 69.3 & 33 & $0.5 I^{* *}$ & 0.009 & $0.31-0.85$ \\
\hline & Others & 10.7 & 6 & 0.80 & 0.611 & $0.33-1.92$ \\
\hline \multirow[t]{2}{*}{ Net use } & No & 456.3 & 229 & 1 & & \\
\hline & Yes & 301.7 & 368 & 1.14 & 0.186 & $0.94-1.40$ \\
\hline \multirow[t]{2}{*}{ Water point } & No & 653.7 & 526 & 1 & & \\
\hline & Yes & 104.3 & 71 & 0.91 & 0.574 & $0.65-1.27$ \\
\hline \multirow[t]{2}{*}{ Farm } & No & 476.7 & 271 & 1 & & \\
\hline & Yes & 281.3 & 326 & $1.46 * * *$ & 0.000 & $1.21-1.78$ \\
\hline \multirow{2}{*}{$\begin{array}{l}\text { Animal } \\
\text { enclosure }\end{array}$} & No & 266.9 & 227 & 1 & & \\
\hline & Yes & 491.1 & 370 & 0.95 & 0.612 & $0.79-1.15$ \\
\hline \multirow[t]{2}{*}{ Breeding site } & No & 697.3 & 548 & 1 & & \\
\hline & Yes & 60.7 & 49 & 1.02 & 0.921 & $0.69-1.50$ \\
\hline \multirow[t]{2}{*}{ Season } & Dry & 443.5 & 225 & 1 & & \\
\hline & Rainy & 314.5 & 372 & $2.19 * * *$ & 0.000 & $1.82-2.65$ \\
\hline
\end{tabular}

* Significant at the 0.05 level, ** Significant at the 0.01 level, *** Significant at the $0.00 \mathrm{I}$ level, PYs $=$ Person years, OR $=$ Odds ratio

at each visit whether the child had been sleeping under a mosquito net since the previous visit. Although a distinction was made between normal mosquito nets and insecticide-treated nets (ITN) during data collection, this was not taken into consideration in the analysis. This was because of the very small number of non-impregnated mosquito nets, as an ongoing community trial provided ITN freely.

Among the factors related to the housing conditions, only the presence of farming activities within a 30-metre radius of the household was associated with increased risk of clinical malaria. The agriculture practice in this region is to dig small furrows between the crops to retain rainfall water for better ground infiltration. Such water bodies combined with the shadow provided by the crops create a suitable environment for vector breeding, thereby increasing the risk of clinical malaria.
The rainy season, as expected is associated with an increase of clinical malaria episodes. In the region where the climate is mostly dry, rainfall, occurring during a specific period of the year, is the main source of breeding sites (open water bodies) for the malaria vector. In contrast, during the dry season, the hot and dry weather is unsuitable for vectors, thereby leading to high vector mortality and reduction in infection. These findings are consistent with those from other studies $[25,26]$

The implication of these findings is that malaria control strategies should be designed to fit location-specific contexts. The distribution of the factors responsible for malaria transmission may lead to different malaria transmission patterns even within such a relatively small geographical entity. At the level of a health district or even for national malaria control policies, it would be very informative to know the risk difference between locations as 
small as a village. Scarce resources for malaria control could then be allocated accordingly. While all villages at risk should receive malaria control measures, high-risk villages can be identified and given priority.

Conducting such studies at the village level in every health district is not only time consuming, but it is costly. Additionally there are very few such studies already available for use. It is, therefore, imperative that well functioning health information systems are established and utilized. In practice, this will require health districts to collect routine health information data series (for example over a three-year period) to assess which villages or localities are at the highest risk, accounting for seasonal variation. This risk assessment may then be utilized to decide to which localities malaria control efforts should be focused rather than distributing resources equally or otherwise based on other criteria.

\section{Authors' contributions}

YY designed and coordinated the implementation of the study. He performed the statistical analysis and drafted the manuscript. CK and VL participated in statistical analysis, writing of the manuscript and interpretation of the findings. RS participated in the design and implementation of the study, and writing of the manuscript. All authors read and approved the final manuscript.

\section{Conflict of interest}

The author(s) declare that they have no competing interests.

\section{Acknowledgements}

The authors would like to express their gratitude to the team of the Centre de Recherche en Santé de Nouna (CRSN) and to the children and families who participated in the study. The German Research Council (DFG) and the UBS Optimus Foundation co-funded the project.

\section{References}

I. WHO: The World Health Report 2002: Reducing risks, promoting healthy life World Health Organization Geneva; 2002.

2. WHO, UNICEF: Africa Malaria Report 2003 World Health Organization, Geneva; 2003.

3. Steketee RW, Nahlen BL, Parise ME, Menendez C: The burden of malaria in pregnancy in malaria-endemic areas. Am J Trop Med Hyg 200I, 64:28-35.

4. Bryce J, Boschi-Pinto C, Shibuya K, Black RE: WHO estimates of the causes of death in children. Lancet 2005, 365: I I47-I I 52.

5. Gilles HM, Warrell DA: Bruce-Chwatt. In Essential Malariology Third edition. Edward Arnold, London; 1993.

6. Wang SJ, Lengeler C, Mtasiwa D, Mshana T, Manane L, Maro G, Tanner M: Rapid urban malaria appraisal (RUMA) II: Epidemiology of urban malaria in Dar es Salaam (Tanzania). Malar J 2006, 5:29.

7. Wang SJ, Lengeler C, Smith TA, Vounatsou P, Diadie DA, Pritroipa X, Convelbo N, Kientga M, Tanner M: Rapid urban malaria appraisal (RUMA) I: epidemiology of urban malaria in Ouagadougou. Malar J 2006, 4:43.

8. Yé Y, Sanou A, Gbangou A, Kouyaté B: Nouna DSS. In INDEPTH. Demography and Health in Developing Countries Volume I. Population, Health and Survival at INDEPTH Sites. IDRC Canada; 2002.
9. Yé Y, Hoshen M, Louis V, Seraphin S, Traore I, Sauerborn R: Housing conditions and Plasmodium falciparum infection: protective effect of iron-sheet roofed houses. Malar J 2006, 5:8.

10. Müller $\mathrm{O}$, Traoré $\mathrm{C}$, Becher $\mathrm{H}$, Kouyate B: Malaria morbidity, treatment-seeking behaviour, and mortality in a cohort of young children in rural Burkina Faso. Trop Med Int Health 2003, 8:290-296.

II. Müller O, Becher H, Baltussen A, Yé Y, Diallo D, Konaté M, Nébié I, Gbangou A, Kouyaté B, Garenne M: Effect of zinc supplementation on Plasmodium falciparum malaria among African children: A randomized controlled trial. BMJ 200I, 322:1567.

12. Baldet T, Diabate A, Guiguemde TR: Malaria transmission in 1999 in the rice field area of the Kou Valley (Bama), (Burkina Faso). Santé 2003, 1 3:55-60.

13. Sissoko MS, Dicko A, Briet OJ, Sissoko M, Sagara I, Keita HD, Sogoba $M$, Rogier C, Toure YT, Doumbo OK: Malaria incidence in relation to rice cultivation in the irrigated Sahel of Mali. Acta Trop 2004, 89:16I-I70.

14. Koudou BG, Tano Y, Doumbia M, Nsanzabana C, Cissé G, Girardin O, Dao D, N'Goran EK, Vounatsou P, Bordmann G, Keiser J, Tanner $M$, Utzinger J: Malaria transmission dynamics in central Cote d'Ivoire: the influence of changing patterns of irrigated rice agriculture. Med Vet Entomol 2005, 19:27-37.

15. Omumbo JA, Guerra CA, Hay SI, Snow RW: The influence of urbanisation on measures of Plasmodium falciparum infection prevalence in East Africa. Acta Trop 2005, 93: ||-2I.

16. Reyburn H, Mbatia R, Drakeley C, Bruce J, Carneiro I, Olomi R, Cox J, Nkya WM, Lemnge M, Greenwood BM, Riley EM: Association of transmission intensity and age with clinical manifestations and case fatality of severe Plasmodium falciparum malaria. JAMA 2005, 293: I46I-I470.

17. Modiano D, Sirima BS, Sawadogo A, Sanou I, Pare J, Konate A, Pagnoni $\mathrm{F}$ : Severe malaria in Burkina Faso: influence of age and transmission level on clinical presentation. Am J Trop Med Hyg 1998, 59:539-542.

18. Modiano D, Chiucchiuini A, Petrarca V, Sirima BS, Luoni G, Roggero MA, Corradin G, Coluzzi M, Esposito F: Interethnic differences in the humoral response to non-repetitive regions of the Plasmodium falciparum circumsporozoite protein. Am J Trop Med Hyg 1999, 61:663-667.

19. Hawley WA, Phillips-Howard PA, ter Kuile FO, Terlouw DJ, Vulule JM, Ombok M, Nahlen BL, Gimnig JE, Kariuki SK, Kolczak MS, Hightower AW: Community-wide effects of permethrin-treated bed nets on child mortality and malaria morbidity in western Kenya. Am J Trop Med Hyg 2003, 68: $121-127$.

20. Lengeler $C$ : Insecticide treated bed nets and curtains for preventing malaria. The Cochrane Library 2004.

21. Armstrong-Schellenberg RM, Abdulla S, Nathan R, Mukasa O, Marchant TJ: Effect of large-scale social marketing of insecticidetreated nets on child survival in rural Tanzania. Lancet 200I, 357:124I-1247.

22. Müller O, Traoré C, Kouyaté B, Yé Y, Frey C, Coulibaly B, Becher H: Effects of insecticide-treated bed net protection during early infancy in an African area of intense malaria transmission: randomized controlled trial. Bull World Health Organ 2006, 84: $120-126$

23. ter Kuile FO, Terlouw DJ, Kariuki SK, Phillips-Howard PA, Mirel LB, Hawley WA, Friedman JF, Shi YP, Kolczak MS, Lal AA, Vulule JM, Nahlen BL: Impact of permethrin-treated bed nets on malaria, anaemia, and growth in infants in an area of intense perennial malaria transmission in western Kenya. Am J Trop Med Hyg 2003, 68:68-77.

24. Koram KA, Owusu-Agyei S, Fryauff DJ, Anto F, Atuguba F, Hodgson A, Hoffman SL, Nkrumah FK: Seasonal profiles of malaria infection, anaemia, and bed net use among age groups and communities in northern Ghana. Trop Med Int Health 2003, 8:793-802.

25. Dicko A, Mantel C, Kouriba B, Sagara I, Thera MA, Doumbia S, Diallo M, Poudiougou B, Diakite M, Doumbo OK: Season, fever prevalence and pyrogenic threshold for malaria disease definition in an endemic area of Mali. Trop Med Int Health 2005, 10:550-556.

26. Shililu J, Ghebremeskel T, Seulu F, Mengistu S, Fekadu H, Zerom M, Asmelash GE, Sintasath D, Mbogo C, Githure J, Brantly E, Beier JC, Novak RJ: Seasonal abundance, vector behavior, and malaria parasite transmission in Eritrea. J Am Mosq Control Assoc 2004, 20:155-164. 